\title{
A Time Series Modelling and Forecasting of Irrigated Area under Major Crops in India using ARIMA Models
}

\author{
Sanjeeta Biswas* and Banjul Bhattacharyya \\ Department of Agricultural Statistics, Bidhan Chandra Krishi Viswavidyalaya, \\ Nadia, Mohanpur-741252, West Bengal, India \\ *Corresponding author
}

\section{A B S T R A C T}

Keywords

Time series,

ARIMA,

Modelling,

forecasting,

Irrigated area under

major crops

Article Info

Accepted:

17 November 2019

Available Online:

10 December 2019
A time series modelling approach is used to forecast the future values. This paper made an attempt to understand the changing pattern of net irrigated area under major crops through the use of statistical analysis of time series. For the study, data with respect to major crops and its total are collected from Ministry of Agriculture \& Farmers Welfare, Govt. of India for the period of 65 years (1950-2015). This paper focused on the best fitted ARIMA model and its forecasting. Validity of the model had also been tested. The efforts were made to forecast, the future irrigated area under major crops for a period up to ten years as accurate as possible. It was found that $\operatorname{ARIMA}(3,1,3)$ fitted well for rice, maize and tobacco whereas ARIMA $(0,1,3)$ model for wheat, total cereal and total pulses crop and for Bajra $(3,1,2)$, total oilseeds crops $(0,1,1)$, sugarcane $(3,1,0)$ and cotton $(2,1,1)$ ARIMA models selected on the basis of satisfying the best fitted model criteria.

\section{Introduction}

Agriculture is the most important sector of Indian economy, where more than $58 \%$ of population depends on agriculture. It is the backbone of Indian economy. Water is a necessary element for successful agriculture. Irrigation practices in agriculture have made a major contribution to food production and food security throughout the world: without irrigation much of the impressive growth in agricultural productivity over the last 50 years could not have been achieved. Development of irrigation source encourages the supply of water with favourable effect on the agricultural growth. Increase in agricultural production and productivity largely depends on the availability of water and that availability of water mainly fulfilled by south west monsoon in Indian subcontinent. The 
farmers get water for their crops either from rainfall or from artificial irrigation such as wells, tanks and canals. In 2000, irrigation contributed to $40 \%$ of the crop area but $70 \%$ of the whole crop production. Improved reliability of facility of water supply through canals or, more significantly through groundwater, has significantly contributed to the increase in agricultural productivity in India (Brown, 2003).Recent studies show that the irrigation needs to play a bigger role towards a goal of achieving a better agricultural productivity and also the national food security (Persaud and Stacey, 2003; Kumar 1998, GOI 1999; Bhaduriet al., 2012). The present study made an attempt to understand the changing pattern of net irrigated area under different crops (crop wise) through the use of statistical analysis of time series. This study is accomplished by using a Box-Jenkins ARIMA time series model in SPSS Software and R coding.Validity of the model has also been tested.This paper focuses mainly on the best fitted ARIMA model and its forecasting.

Box and Jenkins (1970) described the BoxJenkins approach to modelling ARIMA processes. Biswas et al., (2014) analysed area, production and productivity data of wheat for Punjab by time-series methodHamjah (2014) discussed the forecasting the rice production in Bangladesh using ARIMA model. Abdullah and Hossain (2015) also discussed forecasting of wheat production in Kushtia district \& Bangladesh by ARIMA model. Khan (2015) used empirical research which forecasts the rice production. Choudharyet al., (2017) attempted to analyse behaviour of area, irrigated area, production and productivity of rice, wheat and maize, under the background of over all food security in India through ARIMA modelling technique. Patowary et al., (2017) aimed to develop a simple linear regression model with ARIMA errors to yearly production of wheat in India for the period of 1960-2016. Hemavathi and Prabakaran (2018) studied the forecasting area, production and productivity of rice in Thanjavur district.

\section{Materials and Methods}

All the data are used in the study relies on secondary data compiled from various published sources. Data with respect to major crops and its total, under irrigated area are selected from the period of 1950-1951 to 2014-15 from Ministry of Agriculture \& Farmers Welfare, Govt. of India and also through the website www.indiastat.com. In order to analyses the irrigated area under major crops in India, data of 65 years from 1951 to 2015 is examined. Rice, maize, wheat, bajra, total cereals, total pulses, total oilseeds, cotton, sugarcane and tobacco are the major crops on which the analysis was done.This present paper is attempting to analyse the various time series models and to estimate the best fitted models for irrigated area by different sources and irrigated area under crops. Also, to examine the nature of each series which has been subjected to get various descriptive statistical measures and trend models is also considered for study.

\section{Descriptive statistics}

Descriptive statistics offer simple summaries about the data and the measures. The descriptive statistics study that used for study is maximum, minimum, mean, median, skewness, kurtosis etc. to describe the pattern of the series and draw a consensus under consideration.

\section{Trend models}

In this study, we have tried different parametric models to describe the series under consideration, which are briefly given here under: 
Linear model: It is one in which all the parameters appear linearly and it is formulated as $X_{t}=a+b t+e_{t}$.

Quadratic model: It can be used to model a series which "takes off" or a series which "dampens". It expressed as $X_{t}=a+b t+c^{2}+$ $e_{t}$.

Cubic model: The equation of cubic model is a $3^{\text {rd }}$ order of polynomial regression equation and it is represented as $X_{t}=a+b t+c t^{2}+d t^{3}+$ $\mathrm{e}_{\mathrm{t}}$.

Exponential model: The equation of exponential model is $\mathrm{Xt}=\mathrm{a}[\operatorname{Exp}(\mathrm{bt})]+$ et.

Logarithmic model: The equation of logarithmic model is given by $X_{t}=a+b l n(t)+$ $\mathrm{e}_{\mathrm{t}}$.

Growth Model: The equation of growth model is given by $(X t)=\exp \left(b_{0}+b_{1} t\right)+e_{t}$

\section{Time series data}

A time series is a sequence of observations which are ordered in time. Time series forecasting is the use of a model to predict future values based on previously observed values.

It consists of three basic model forms: (1) the Moving Average model MA(q), in which q is the order of the moving average; (2) an autoregressive model AR (p), in which $\mathrm{p}$ is the order of the auto regression; and (3) the auto regression Moving Average model ARMA $(\mathrm{p}, \mathrm{q})$.

\section{Box-Jenkins models}

The basic principle behind this methodology is that the present value of the series is any way related with its past values. Box-Jenkins (1970) Analysis refers to a systematic method of identifying, fitting, checking, and using integrated autoregressive, moving average (ARIMA) time series models.

The method is appropriate for time series of medium to long length (at least 30 observations).It is used for time series analysis which is technically known as the ARIMA methodology.

\section{Autoregressive integrated moving average model (ARIMA)}

ARIMA models are, in theory, the most general class of models for forecasting a time series which can be made stationary by transformation or differencing.

In fact, the easiest way for ARIMA models is as fine-tuned versions of random walk and random trend models: the fine-tuning consists of adding lags of the differenced series or lags of the forecast errors to the prediction equation, as needed to remove any last traces of autocorrelation from the forecast errors.

Lags of the differenced series appearing in the forecasting equation are called "autoregressive" (AR) terms, lags of the forecast errors is defined as "moving average" (MA) and a time series which needs to be differenced to be made stationary is said to be an "integrated" which is a stationary series.

A non-seasonal ARIMA model can be classified as an "ARIMA" i.e. p,d,q model, where:

$p$ is the number of autoregressive terms,

$\mathrm{d}$ is the number of non-seasonal differences, and

$\mathrm{q}$ is the number of lagged forecast errors for prediction.

ARIMA in general form is as follows: 
$\Delta^{d} Z_{\mathrm{t}}=\mathrm{c}+\left(\varphi_{1} \Delta^{d} \mathrm{Z}_{\mathrm{t}-1+\ldots+} \varphi_{p} \Delta^{d} \mathrm{Z}_{\mathrm{t}-\mathrm{p})}-\left(\theta_{1} \mathrm{e}_{\mathrm{t}-1}\right.\right.$ $\left.+\ldots+\theta_{q} e_{t-q}\right)+e_{t}$

Where $\Delta$ denotes differences operator like $\Delta \mathrm{Z}_{\mathrm{t}}=\mathrm{Z}_{\mathrm{t}}-\mathrm{Z}_{\mathrm{t}-1}$ (data form of first order differentiation)

$\Delta^{2} \mathrm{Z}_{\mathrm{t}-1}=\Delta \mathrm{Z}_{\mathrm{t}}-\Delta \mathrm{Z}_{\mathrm{t}-1}$ (data form of first order differentiation)

Here, $\mathrm{Z}_{\mathrm{t}-1} \ldots \mathrm{Z}_{\mathrm{t}-\mathrm{p}}$ are values of past series with lag $1 \ldots$ p respectively.

ARIMA consists of following steps are as follows:

\section{Identification}

The problem is to find out the appropriate values of $\mathrm{p}, \mathrm{d}$ and $\mathrm{q}$. One of the important tools for identification are the autocorrelation function $(\mathrm{ACF})$, the partial autocorrelation function (PACF), and the resulting correlograms, which are simply the plots of $\mathrm{ACF}$ and PACFs against the lag length.

\section{Estimation}

After identifying the appropriate values of $p$ and $\mathrm{q}$ the next step is to estimate the parameters of the autoregressive and moving average terms included in the model. Sometime this calculation can be done by simple least squares.

\section{Diagnostic checking}

In this step one can see the whether the chosen model fits the data reasonably well.

\section{Stationarity test}

For stationarity test, two test is used i.e. Augmented-Dickey-Fuller (ADF) test and Kwiatkowski-Phillips-Schmidt- Shin (KPSS) tests are used to check whether the data series is stationary or not.

\section{Model formulation}

The whole period under consideration (19512015) has been divided into three parts.

The model formulation period (1951-2012).

Model validation period (2013-2015).

Forecasting period up to 2020.

\section{Model selection criteria}

Box- Jenkins model best model is selected on the basis of maximum $\mathrm{R}^{2}$, minimum root mean square error (RMSE), minimum mean absolute percentage error (MAPE), minimum of maximum average percentage error (MaxAPE), minimum of maximum absolute error (MaxAE), minimum of Normalized BIC. Any model which has fulfilled most of the above criteria is selected. This section provides definitions of the goodness-of-fit measures used in time series modelling.

\section{Diagnostic test of residuals}

\section{JarqueBera (JB) test}

The Jarque-Bera Test, a type of Lagrange multiplier test, is a test for normality. The Jarque-Bera test is a goodness-of-fit test of whether sample data have the skewness and kurtosis matching a normal distribution. The JB test is always non negative.

The $J B$ test is defined as

$\mathrm{JB}=\frac{n-k+1}{6}\left(\mathrm{~S}^{2}+\frac{(\mathrm{C}-3)^{2}}{4}\right)$

\section{Ljung-Box statistic}

The Ljung- Box test (1978) is a diagnostic tool used to test the lack of fit of a time series model. The test is applied to the residuals of a time series after fitting an ARMA (p,q) model to the data. 
It is given by $\left.\mathrm{LB}=\mathrm{n}(\mathrm{n}+2) \sum_{k=1}^{m} \frac{\hat{\rho}_{k}^{\mathrm{N}}}{n-k}\right) \sim X^{2} \mathrm{~m}$

\section{Results and Discussion}

Table 1 displays descriptive statistics with respect to irrigated area under major crops in India from 1951 to 2015.The descriptive statistics demonstrates the mean, maximum and minimum values along with other statistical properties.It is noticed that the irrigated area under rice has increased from 9.65 million hectare to 26.58 million hectare with an average of 17.87 million hectare and registered a simple growth rate (SGR) of almost $2.65 \%$ per annum. In case of wheat, irrigated area has been increased from 3.40 million hectare to 30.21 million hectare with an average of 15.38 million hectare having SGR of almost $12.31 \%$ per annum. Similarly, the irrigated area under maize has increased from 0.37 million hectare to 2.45 million hectare and for bajra irrigated area increases from 0.25 million hectare to 0.99 million hectare with an average of 1.15 million hectare for maize and 0.57 million hectare and registered SGR of almost $8.35 \%$ per annum for maize and $1.91 \%$ per annum for bajra. It is observed that the irrigated area is increased from 16.38 million hectares to 61.22 million hectares (total cereals), 1.71 million hectares to 4.69 million hectares (total oilseeds), 0.98 million hectares to 5.27 million hectares (sugarcane), 0.47 million hectares to 4.37 million hectares and 0.03 million hectares to 0.28 (tobacco) with an average of $36.94,2.50$, $3.65,2.88,2.16$ and 0.14 million hectares respectively, registered SGR per annum of almost $4.27 \%, 1.91 \%, 5.54 \%, 5.06 \%, 12.79 \%$ and $9.47 \%$ per annum respectively. It is also noticed that the simple growth rate of irrigated under cotton is comparatively higher than other crops which is followed by wheat. The irrigated area under total pulses has registered positive skewness and positive kurtosis, which means that there is an increasing order during early half of the study period and which is not remain steady for a long time. The irrigated area under wheat and cotton is showing negative skewness and negative kurtosis, which indicates that there is a marginal and consistent of irrigated area during the later phase of investigation. But, other crops are showing the positive skewness and negative kurtosis which means that there is an increasing order during early half of the study period and remain steady for a long time.

\section{Trending behaviour regarding irrigated area under major crops}

All estimated parameter and goodness of fit by those models are presented in table 2. For testing parametric models, best model is selected for irrigated area under crops on the basis of following criteria: significant of parameters at $5 \%$, maximum $\mathrm{R}^{2}$ value and minimum value of RMSE. It is observed that among the rest of the models, linear and growth models fitted well. In case of bajra, cotton, sugarcane and tobacco linear model is best fitted based on the significant of the parameter estimate and goodness of fit. It is found that all parameters are significant with the value of maximum $\mathrm{R}^{2}$ and minimum values of RMSE (Fig. 1).

Bajra with the value of $R^{2}(0.770)$ with minimum RSME (0.085). In case of Cotton, the value of $R^{2}(0.955)$ with minimum RSME (0.217). Similarly, sugarcane with the value of $\mathrm{R}^{2}(0.960)$ with minimum RSME (0.057) and tobacco with the value of $\mathrm{R}^{2}(0.907)$ with minimum RSME (0.018). All fitted crops were negatively significant. While in rice, maize, total pulses and total oilseeds, growth model is fitted well significantly with the value of $\mathrm{R}^{2}$ and minimum values of RMSE. Rice with the value of maximum $\mathrm{R}^{2}(0.985)$ with minimum RSME (0.2). Maize, total pulses and total oilseeds with the value of maximum $\mathrm{R}^{2}$ (0.893), $\mathrm{R}^{2}(0.682), \mathrm{R}^{2}(0.985)$ and minimum RSME (0.161), (0.845) and (0.460) respectively showing negatively significant. 
Similarly, for wheat with $\mathrm{R}^{2}(0.985)$ and RMSE (0.19), for total cereals $\mathrm{R}^{2}(0.989)$ with RMSE (0.06), cubic model is fitted with negatively significant. The observed value fitted well with predicted value with suitable models. For applying the most time series models, the dataset must be checked of its stationarity. Augmented Dickey Fuller (ADF) test and KPSS test are applied for testing the stationarity. From table 3, it is observed that all the datasets are presented as non-stationary which is insignificant at 5\% level of significance as the null hypothesis is not rejected as the p-value is greater than 0.05 that means the null hypothesis is not stationary.

The residual ACF and PACF graphs of the original series are also clearly indicated that none of the series is stationary in nature and first order differencing is sufficient to make these stationary i.e., $\mathrm{d}=1$. As per autocorrelation and partial autocorrelation consideration, the best fitted ARIMA (p, q, q) models are selected for different sources of irrigation in India and compared to each other as depicted in table 4 .

All the best fitted models are selected based on maximum $\mathrm{R}^{2}$, value and minimum values of RMSE, MAPE, MAE, MaxAPE, MaxAE. To check the autocorrelation assumption, Ljung- box test is used. It is found that ARIMA $(3,1,3)$ are fitted well for rice, maize and tobacco with maximum $\mathrm{R}^{2,}$ minimum RMSE, MAPE, MAE, MaxAPE, MaxAE whereas $(0,1,3)$ has selected best fitted model for wheat, total cereal crops and total pulses crop. In case of Bajra $(3,1,2)$, for total oilseeds crops $(0,1,1)$, for sugarcane $(3,1,0)$ and for cotton $(2,1,1)$ are selected ARIMA models on the basis of satisfying the best fitted model criteria. Residuals of this model is also satisfied both the normality and randomness assumptions. All the estimated parameters are significant at $1 \%$ level of significance. From residual ACF and PACF plots of ARIMA models for all major crops and its total, it is as shown in figure 2.

\section{Model estimation and validation}

Among the selected models, ARIMA models fit well for all dataset and finally which can be used for forecast of corresponding variables. There are two kinds of forecast i.e. in sample forecast and out sample forecast. From table 5, it is clearly observed that in sample forecast are from 2013 to 2015 and out sample forecast are from 2016 to 2022. In case of in sample forecast, the predicted values are for all dataset are almost close to actual values. The irrigated area under rice is forecasted as 28.57 million hectares for the year 2022 and 27.90 million hectares for the year 2020 while wheat has been forecasted as 32.20 (2020) and 33.27 (2022) million hectares.

In case of Maize was forecasted as 2.36 (2020) and 2.43 (2022) million hectares, for Bajra forecasted as 0.84 (2020) and 0.83 (2022) million hectares, for total cereals crops forecasted as 64.00 (2020) and 65.47 (2022) million hectares, for total pulse crops forecasted as 4.05 (2020) and 4.12 (2022) million hectares, for total oilseeds crops forecasted as 8.60 (2020) and 8.79 (2022) million hectares, for cotton forecasted as 4.81 (2020) and 4.94 (2022) million hectares, for sugarcane forecasted as 5.46 (2020) and 5.69 (2022) million hectares and for tobacco forecasted as 0.23 (2020) and 0.24 (2022) million hectares is observed. It is found that the irrigated area under crop increased in the year 2022 . 
Table.1 Descriptive statistics of irrigated area under different crops in India

\begin{tabular}{|c|c|c|c|c|c|c|c|c|c|}
\hline Crops & Range & Max. & Min. & Mean & SD & Skew. & Kurt. & $\begin{array}{c}\text { JB } \\
\text { test }\end{array}$ & SGR\% \\
\hline Rice & 16.93 & 26.58 & 9.65 & 17.87 & 5.21 & 0.20 & -1.27 & 0.06 & 2.65 \\
\hline Wheat & 26.81 & 30.21 & 3.40 & 15.38 & 8.51 & -0.053 & -1.38 & 0.04 & 12.31 \\
\hline Maize & 2.08 & 2.45 & 0.37 & 1.15 & 0.52 & 0.55 & -0.12 & 0.09 & 8.35 \\
\hline Bajra & 0.30 & 0.99 & 0.25 & 0.57 & 0.17 & 0.01 & -0.67 & 0.41 & 1.91 \\
\hline Total cereals & 44.84 & 61.22 & 16.38 & 36.94 & 13.76 & 0.52 & -1.31 & 0.06 & 4.27 \\
\hline Total pulses & 2.98 & 4.69 & 1.71 & 2.50 & 0.74 & 1.16 & 0.34 & 0.06 & 1.91 \\
\hline Total oilseeds & 8.57 & 8.67 & 0.09 & 3.65 & 2.98 & 0.30 & -1.60 & 0.02 & 5.54 \\
\hline Sugarcane & 4.29 & 5.27 & 0.98 & 2.888 & 1.26 & 0.31 & -1.20 & 0.05 & 5.06 \\
\hline $\begin{array}{c}\text { Cotton } \\
\text { Tobacco }\end{array}$ & 3.90 & 4.37 & 0.47 & 2.16 & 1.01 & 0.203 & -0.85 & 0.16 & 12.79 \\
\hline Note: SGR- Simple Growth Rate & 0.28 & 0.03 & 0.14 & 0.06 & -0.13 & -1.11 & 0.10 & 9.47 \\
\hline
\end{tabular}

Table.2 Fitting of linear and non-linear regression models of irrigated area under different crops in India

\begin{tabular}{|c|c|c|c|c|c|c|c|c|c|}
\hline \multirow{2}{*}{ Crops } & \multirow{2}{*}{ Model } & \multicolumn{3}{|c|}{ Parameter Estimates } & \multicolumn{3}{c|}{ Goodness of fit } & \multirow{2}{*}{ Sig. } \\
\cline { 3 - 10 } & & $\mathbf{a}$ & $\mathbf{b}_{\mathbf{1}}$ & $\mathbf{b}_{\mathbf{2}}$ & $\mathbf{b}_{\mathbf{3}}$ & $\mathbf{R M S E}$ & $\mathbf{R}^{\mathbf{2}}$ & Adjusted R $^{2}$ & \\
\hline Rice & Growth & -28.23 & 0.016 & & & 0.049 & 0.974 & 0.973 & 0.00 \\
\hline Wheat & Cubic & -869.23 & 0.446 & -2.208 & 1.128 & 0.20 & 0.985 & 0.983 & 0.00 \\
\hline Maize & Growth & -48.50 & 0.024 & & & 0.161 & 0.893 & 0.891 & 0.00 \\
\hline Bajra & Linear & -15.65 & 0.008 & & & 0.085 & 0.770 & 0.767 & 0.00 \\
\hline Total cereals & Cubic & -441.84 & -2.36 & -1.19 & 0.0006 & 1.455 & 0.989 & 0.987 & 0.00 \\
\hline Total pulses & Growth & -22.50 & 0.012 & & & 0.153 & 0.682 & 0.677 & 0.00 \\
\hline Total oilseeds & Growth & -120.04 & 0.061 & & & 0.46 & 0.845 & 0.843 & 0.00 \\
\hline Sugarcane & Linear & -127.32 & 0.066 & & & 0.057 & 0.960 & 0.959 & 0.00 \\
\hline Cotton & Linear & -102.29 & 0.053 & & & 0.217 & 0.955 & 0.954 & 0.00 \\
\hline Tobacco & Linear & -5.922 & 0.003 & & & .018 & 0.907 & 0.906 & 0.00 \\
\hline
\end{tabular}

Table.3 ADF test for irrigated area under major crops in India

\begin{tabular}{|c|c|c|c|c|c|c|}
\hline Crops & ADF value & P val & conclusion & KPSS value & P val & Conclusion \\
\hline Rice & -3.420 & 0.060 & Non stationary & 1.701 & 0.01 & Non stationary \\
\hline Wheat & -2.334 & 0.439 & Non stationary & 1.712 & 0.01 & Non stationary \\
\hline Maize & -1.078 & 0.918 & Non stationary & 1.567 & 0.01 & Non stationary \\
\hline Bajra & -3.044 & 0.151 & Non stationary & 1.449 & 0.01 & Non stationary \\
\hline Total cereals & -3.911 & 0.062 & Non stationary & 1.723 & 0.01 & Non stationary \\
\hline Total pulses & -0.321 & 0.986 & Non stationary & 1.321 & 0.01 & Non stationary \\
\hline Total oilseeds & -2.289 & 0.457 & Non stationary & 1.600 & 0.01 & Non stationary \\
\hline Cotton & -3.515 & 0.047 & Non stationary & 1.680 & 0.01 & Non stationary \\
\hline Sugarcane & -2.035 & 0.560 & Non stationary & 1.693 & 0.01 & Non stationary \\
\hline Tobacco & -2.584 & 0.338 & Non stationary & 1.693 & 0.01 & Non stationary \\
\hline
\end{tabular}


Table.4 Best fitted ARIMA models for irrigated area under major crops in India

\begin{tabular}{|c|c|c|c|c|c|c|c|c|c|c|}
\hline \multirow[t]{2}{*}{ Crops } & \multirow[t]{2}{*}{$\begin{array}{c}\text { ARIMA } \\
\text { Model }\end{array}$} & \multicolumn{7}{|c|}{ Model selection criteria } & \multicolumn{2}{|c|}{$\begin{array}{l}\text { Ljung Box Test } \\
\text { for residuals }\end{array}$} \\
\hline & & $\mathbf{R}^{2}$ & RMSE & MAPE & MAE & MaxAPE & MaxAE & NBIC & $\chi^{2}$ & P val \\
\hline Rice & $3,1,3$ & 0.973 & 0.849 & 2.820 & 0.527 & 13.77 & 2.913 & 0.535 & 11.254 & 0.507 \\
\hline Wheat & $0,1,3$ & 0.995 & 0.610 & 3.682 & 0.437 & 11.973 & 1.793 & -0.651 & 5.244 & 0.990 \\
\hline Maize & $3,1,3$ & 0.912 & 0.144 & 9.768 & 0.098 & 31.190 & 0.329 & -3.015 & 10.512 & 0.571 \\
\hline Bajra & $3,1,2$ & 0.873 & 0.069 & 9.045 & 0.051 & 24.460 & 0.133 & -4.563 & 12.80 & 0.463 \\
\hline Total cereals & $0,1,3$ & 0.993 & 1.074 & 2.286 & 0.792 & 7.600 & 3.570 & 0.563 & 7.995 & 0.924 \\
\hline Total pulses & $0,1,3$ & 0.921 & 0.190 & 5.990 & 0.141 & 19.341 & 0.431 & -2.899 & 17.22 & 0.305 \\
\hline Total oilseeds & $0,1,1$ & 0.972 & 0.497 & 4.290 & 0.328 & 17.37 & 1.633 & -1.124 & 13.20 & 0.722 \\
\hline Cotton & $2,1,1$ & 0.959 & 0.197 & 5.632 & 0.125 & 23.41 & 0.675 & -2.700 & 21.64 & 0.117 \\
\hline Sugarcane & $3,1,0$ & 0.985 & 0.155 & 4.444 & 0.110 & 25.387 & 0.365 & -3.113 & 9.115 & 0.871 \\
\hline Tobacco & $3,1,3$ & 0.932 & 0.015 & 7.782 & 0.009 & 47.71 & 0.055 & -7.730 & 5.848 & 0.970 \\
\hline
\end{tabular}

Table.5(a) Model Validation and Forecasting for irrigated area under major crops in India

\begin{tabular}{|c|c|c|c|c|c|c|c|c|c|c|}
\hline \multirow[t]{2}{*}{ Year } & \multicolumn{2}{|c|}{ Rice } & \multicolumn{2}{|c|}{ Wheat } & \multicolumn{2}{|c|}{ Maize } & \multicolumn{2}{|c|}{ Bajra } & \multicolumn{2}{|c|}{ Total cereals } \\
\hline & $\mathbf{A}$ & $\mathbf{P}$ & A & $\mathbf{P}$ & $\mathbf{A}$ & $\mathbf{P}$ & $\mathbf{A}$ & $\mathbf{P}$ & A & $\mathbf{P}$ \\
\hline 2013 & 24.992 & 26.20 & 28.498 & 28.64 & 2.221 & 2.12 & 0.699 & 0.80 & 57.675 & 60.11 \\
\hline 2014 & 26.516 & 26.47 & 29.369 & 29.07 & 2.449 & 2.19 & 0.732 & 0.80 & 60.281 & 59.85 \\
\hline 2015 & 26.582 & 26.45 & 30.214 & 29.59 & 2.343 & 2.25 & 0.747 & 0.81 & 61.222 & 60.33 \\
\hline 2016 & . & 27.06 & & 30.10 & . & 2.24 & . & 0.78 & . & 61.07 \\
\hline 2017 & . & 27.13 & . & 30.62 & . & 2.25 & . & 0.77 & . & 61.80 \\
\hline 2018 & . & 27.39 & . & 31.15 & . & 2.31 & . & 0.78 & . & 62.53 \\
\hline 2019 & . & 27.83 & . & 31.67 & . & 2.36 & . & 0.81 & . & 63.27 \\
\hline 2020 & . & 27.90 & . & 32.20 & . & 2.36 & . & 0.84 & . & 64.00 \\
\hline 2021 & . & 28.29 & . & 32.73 & . & 2.38 & . & 0.85 & . & 64.73 \\
\hline 2022 & . & 28.57 & . & 33.27 & . & 2.43 & . & 0.83 & . & 65.47 \\
\hline \multicolumn{11}{|c|}{ Note: $\mathbf{A}=$ Actual production. $\mathbf{P}=$ Predicted production. $\quad$ million hectare } \\
\hline
\end{tabular}

Table.5(b) Model Validation and Forecasting for irrigated area under major crops in India

\begin{tabular}{|c|c|c|c|c|c|c|c|c|c|c|}
\hline \multirow[t]{2}{*}{ Year } & \multicolumn{2}{|c|}{ Total pulses } & \multicolumn{2}{|c|}{ Total oilseeds } & \multicolumn{2}{|c|}{ Cotton } & \multicolumn{2}{|c|}{ Sugarcane } & \multicolumn{2}{|c|}{ Tobacco } \\
\hline & $\mathbf{A}$ & $\mathbf{P}$ & $\mathbf{A}$ & $\mathbf{P}$ & $\mathbf{A}$ & $\mathbf{P}$ & $\mathbf{A}$ & $\mathbf{P}$ & $\mathbf{A}$ & $\mathbf{P}$ \\
\hline 2013 & 4.068 & 3.84 & 8.173 & 7.91 & 4.016 & 4.47 & 5.180 & 5.070 & 0.229 & 0.210 \\
\hline 2014 & 4.690 & 3.86 & 8.220 & 8.01 & 3.868 & 4.37 & 5.267 & 4.760 & 0.236 & 0.220 \\
\hline 2015 & 4.312 & 3.90 & 7.778 & 8.11 & 4.272 & 4.49 & 5.018 & 4.931 & 0.275 & 0.220 \\
\hline 2016 & . & 3.93 & . & 8.21 & . & 4.57 & . & 4.382 & . & 0.230 \\
\hline 2017 & . & 3.96 & . & 8.30 & . & 4.61 & . & 5.288 & . & 0.220 \\
\hline 2018 & . & 3.99 & . & 8.40 & . & 4.68 & . & 5.254 & . & 0.220 \\
\hline 2019 & . & 4.02 & . & 8.50 & . & 4.75 & . & 5.241 & . & 0.230 \\
\hline 2020 & . & 4.05 & . & 8.60 & . & 4.81 & . & 5.461 & & 0.230 \\
\hline 2021 & . & 4.09 & . & 8.69 & . & 4.87 & . & 5.670 & . & 0.230 \\
\hline 2022 & . & 4.12 & . & 8.79 & & 4.94 & & 5.690 & & 0.240 \\
\hline \multicolumn{11}{|c|}{ Note: $\mathbf{A}=$ Actual production. $\mathbf{P}=$ Predicted production. $\quad$ million hectare } \\
\hline
\end{tabular}


Fig.1 Observed and Expected trend of irrigated area under major crops in India

Rice

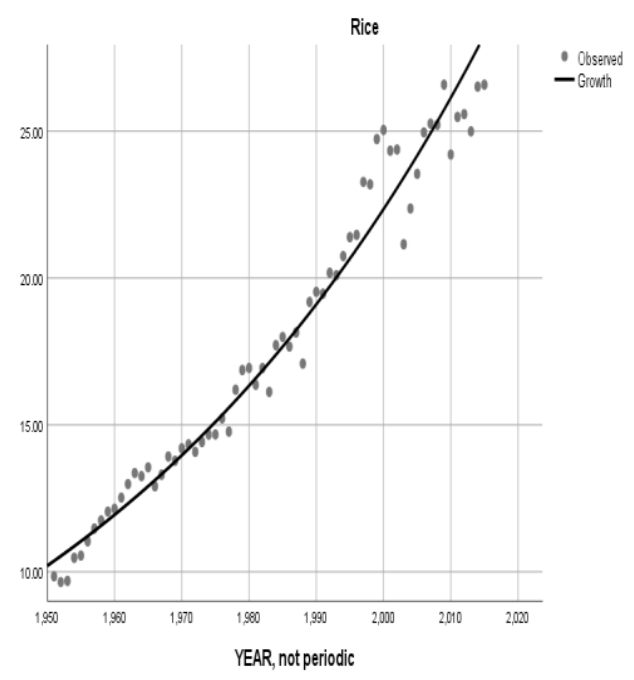

Bajra

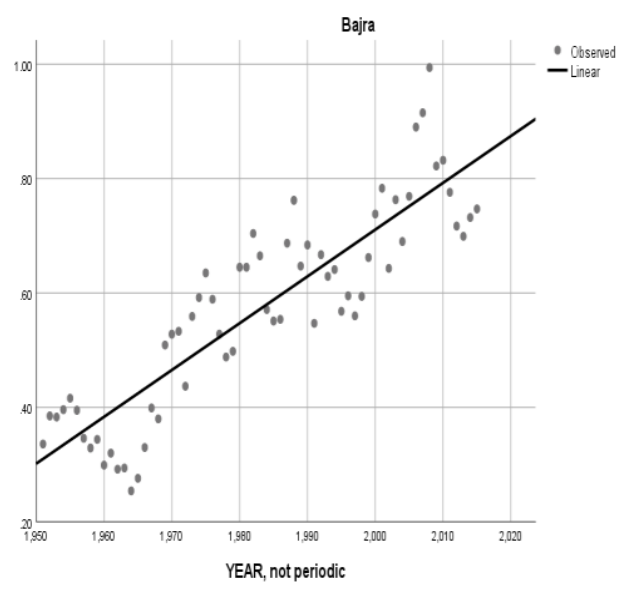

Wheat

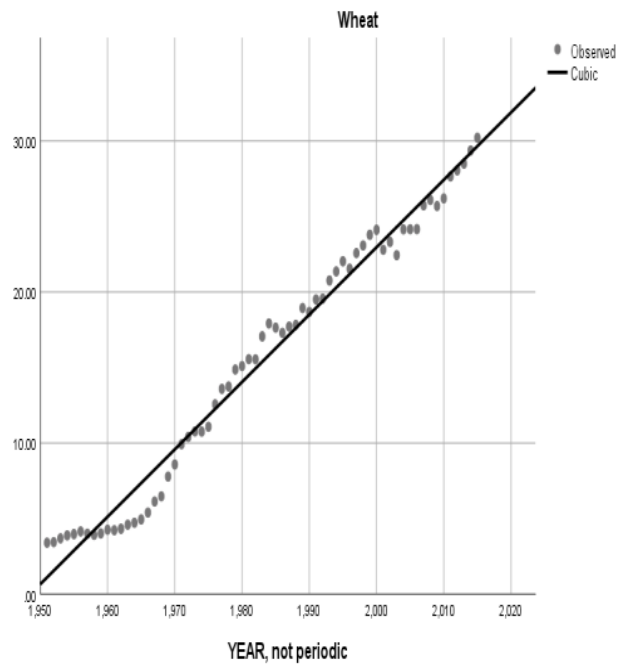

Maize

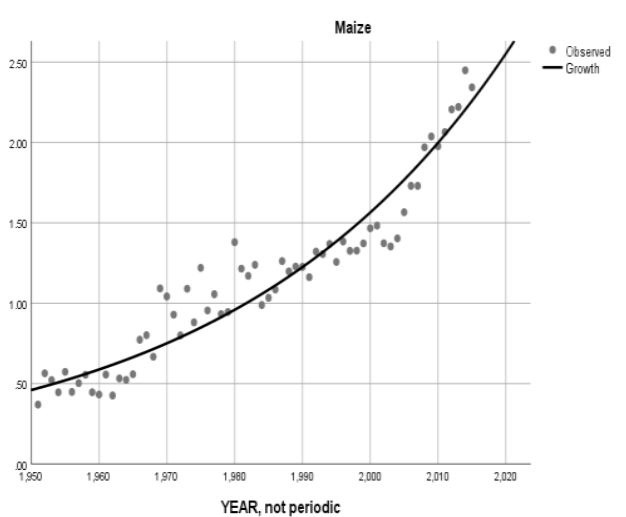




\section{Total cereals}

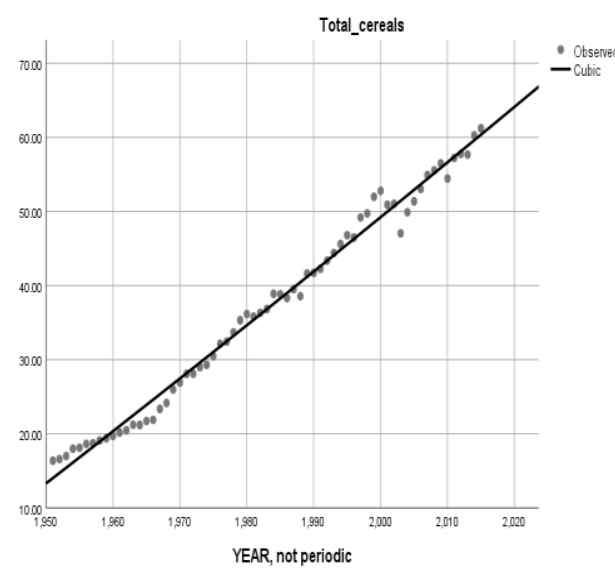

Total Oilseeds
Total pulses

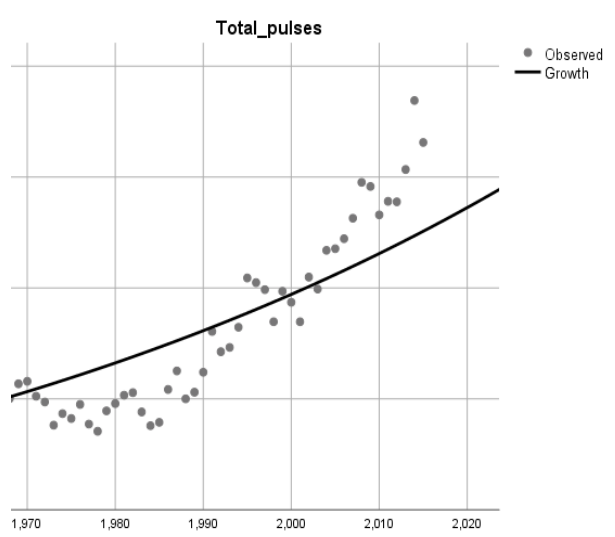

Sugarcane

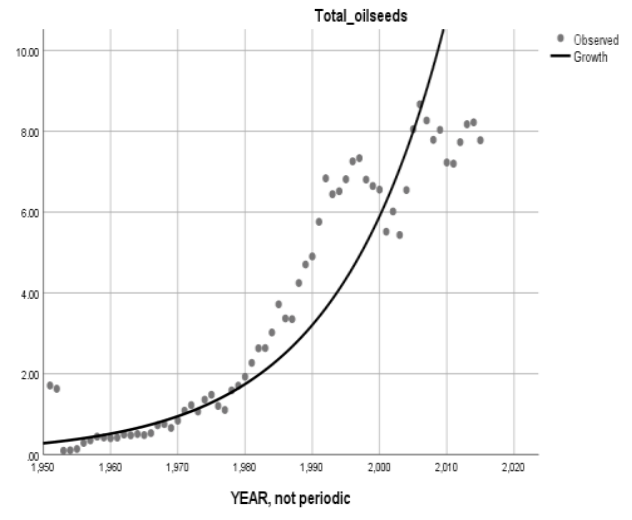

Cotton

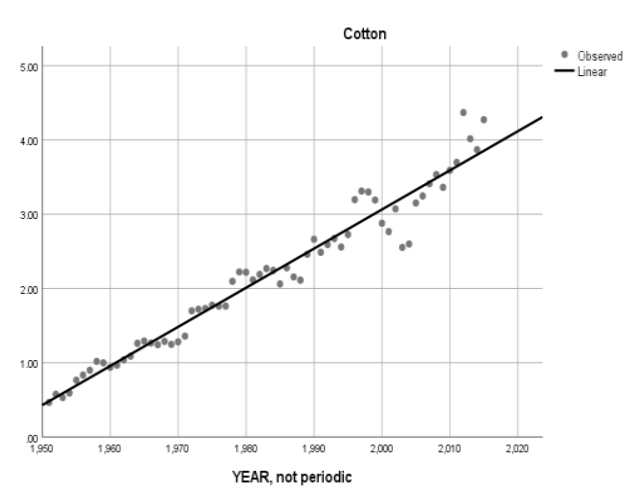

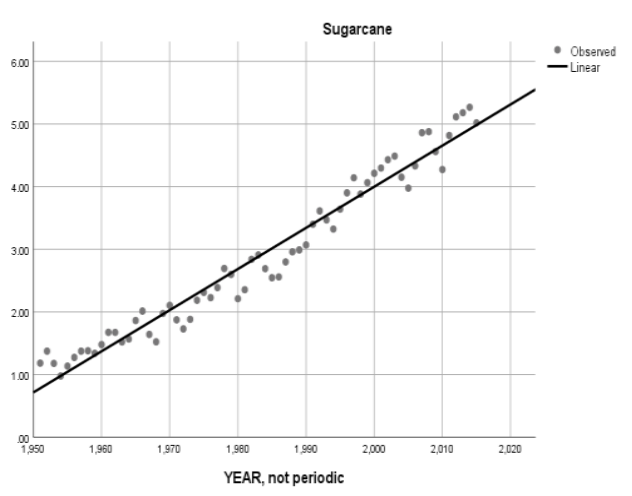

Tobacco

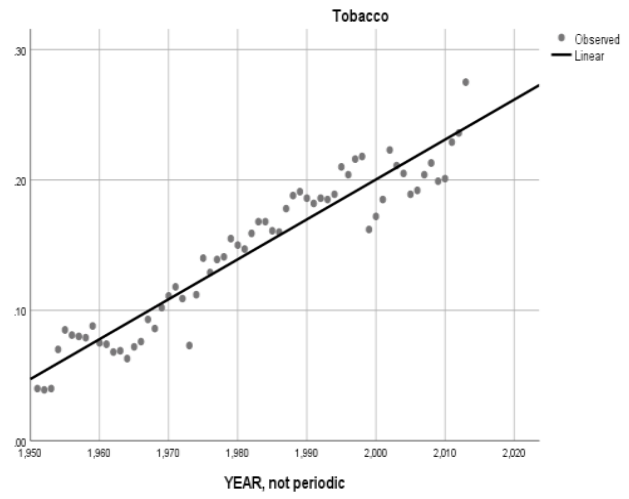


Fig.2 Model residual ACF and PACF plots of best fitted ARIMA models for irrigated area under major crops

Rice

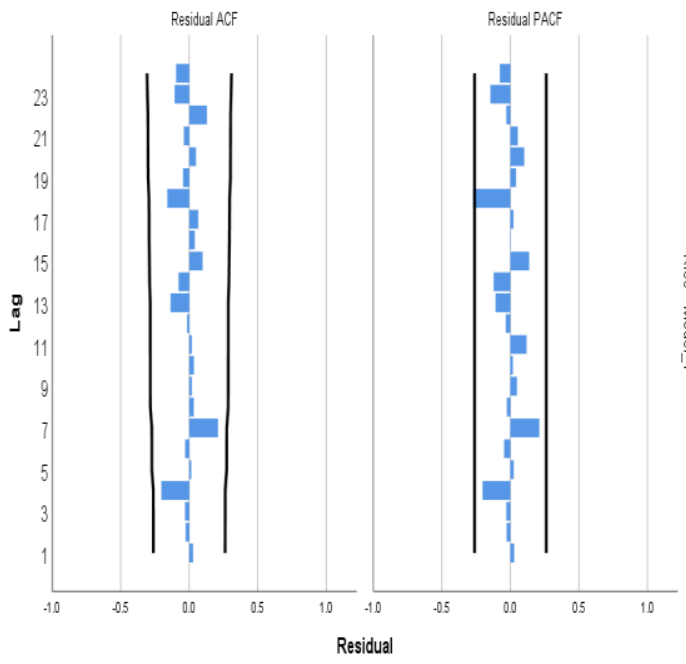

Maize

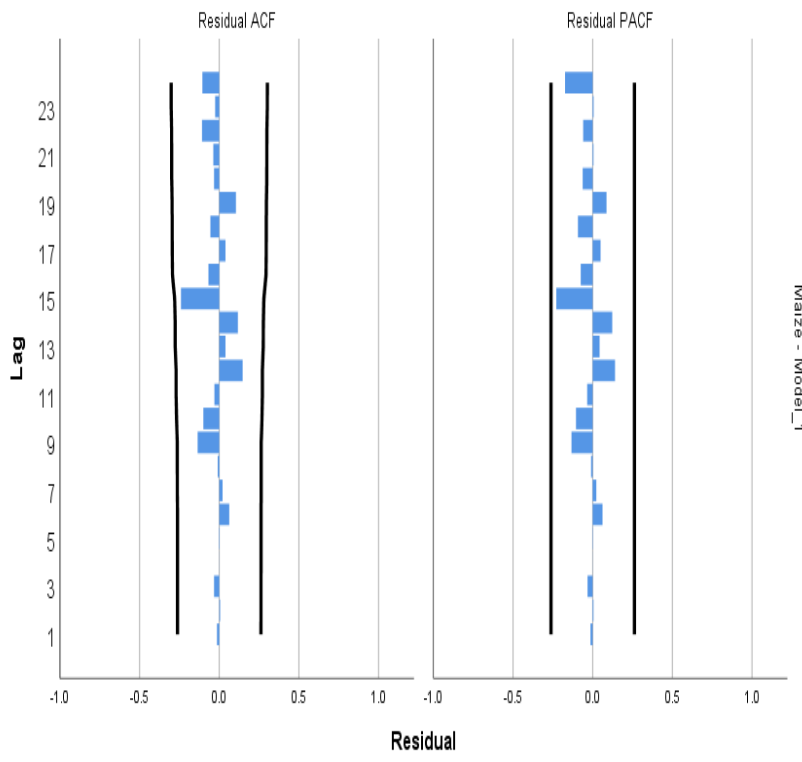

Wheat

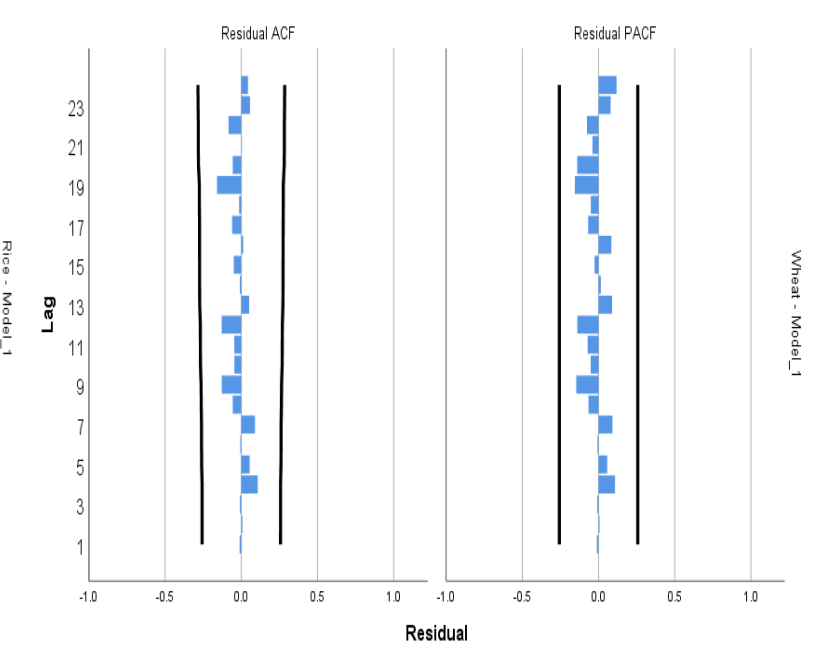

Bajra

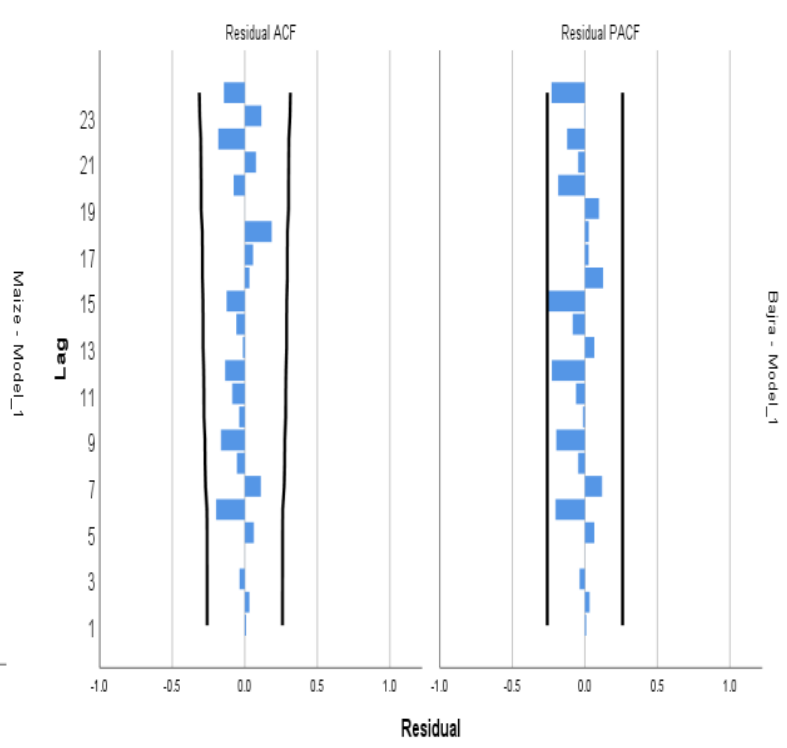


Total cereals

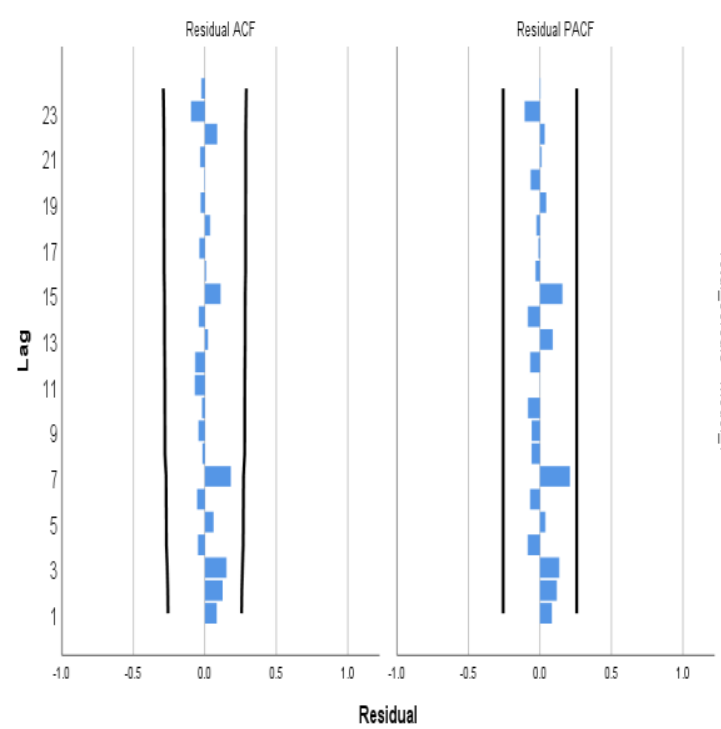

Total oilseeds

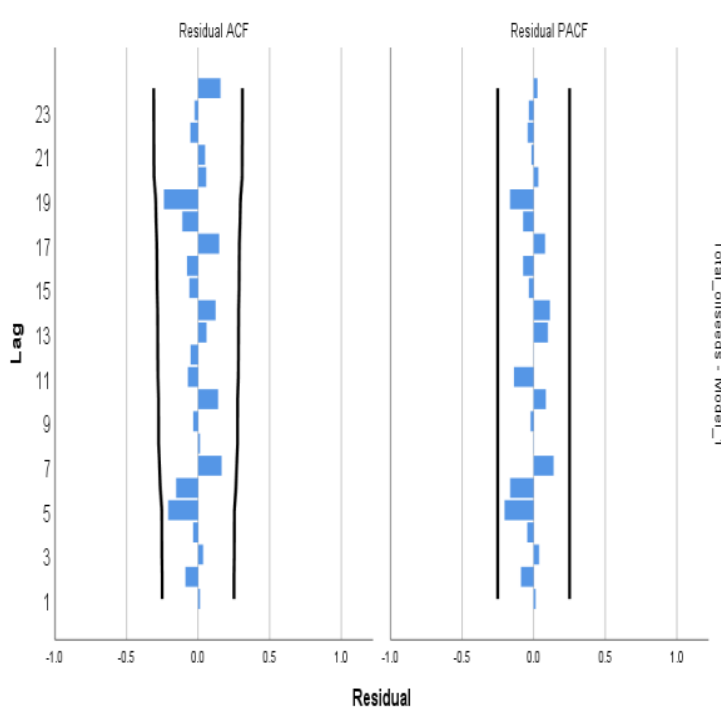

Total Pulses

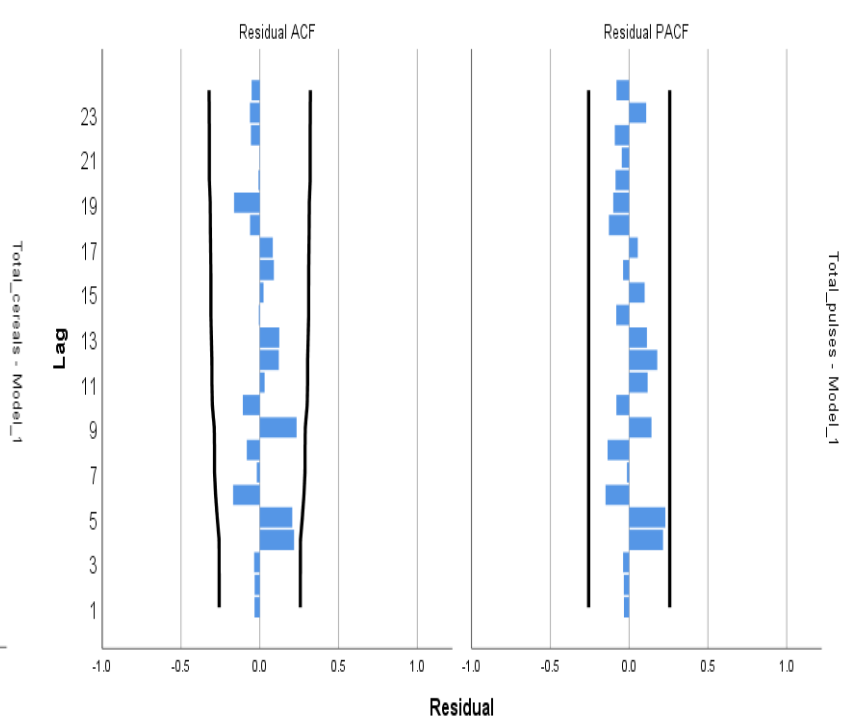

Cotton

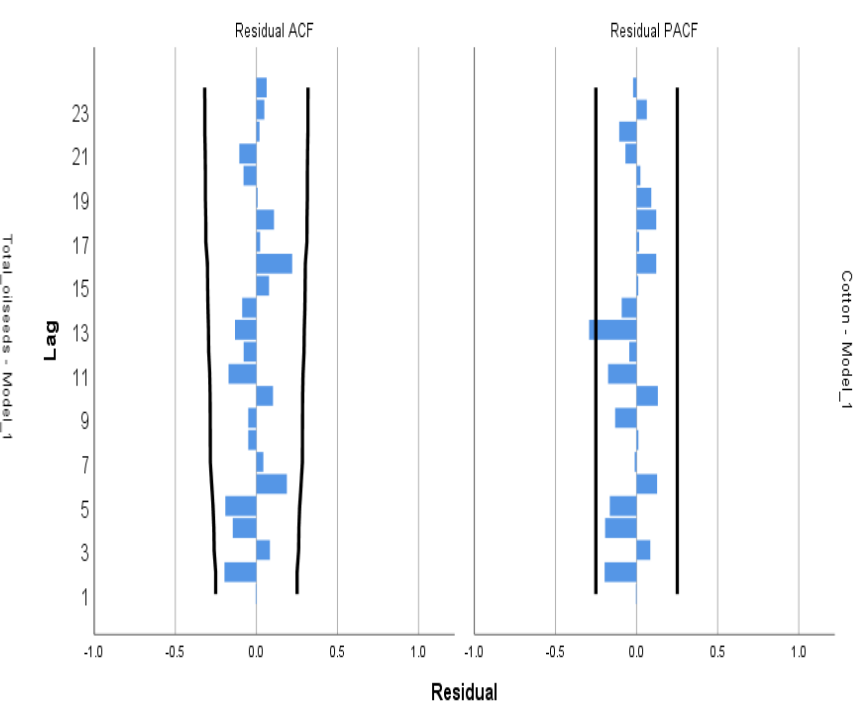


Sugarcane

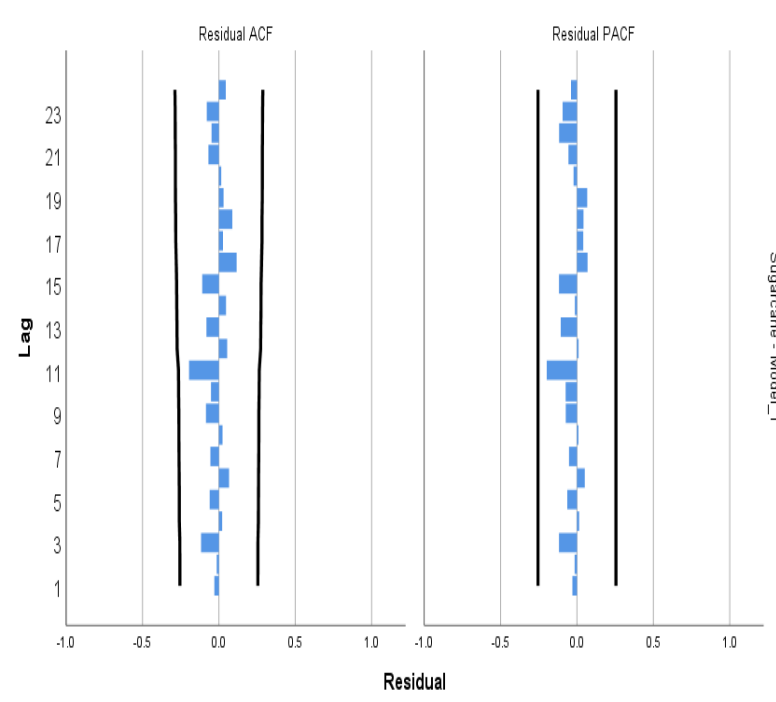

Tobacco

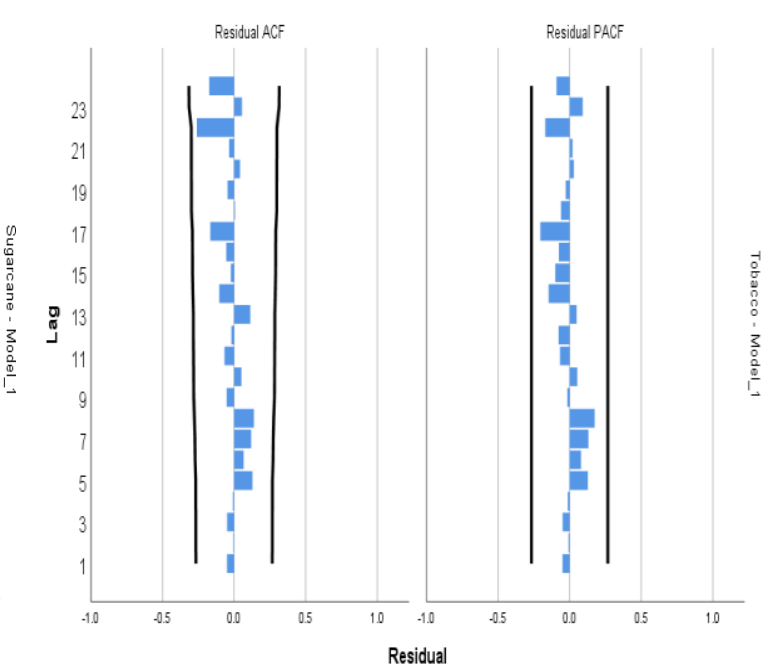

Fig.3 Forecasting of irrigated area under different crops in India using best fitted ARIMA models

Rice

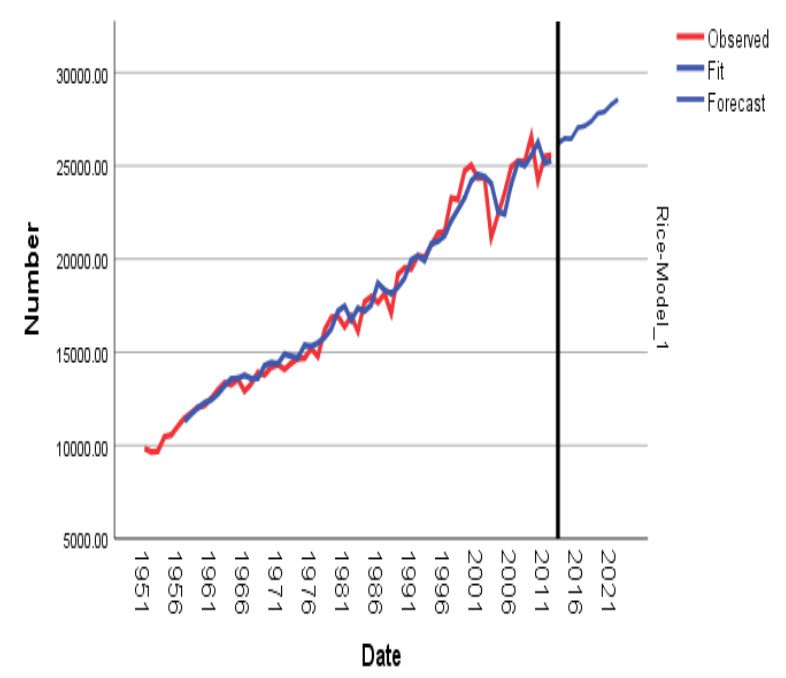

Wheat

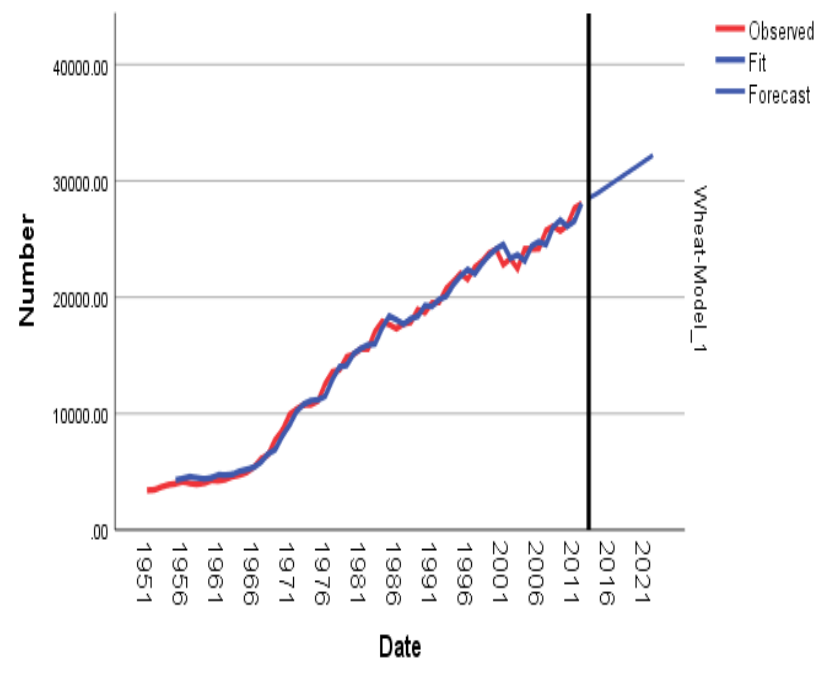



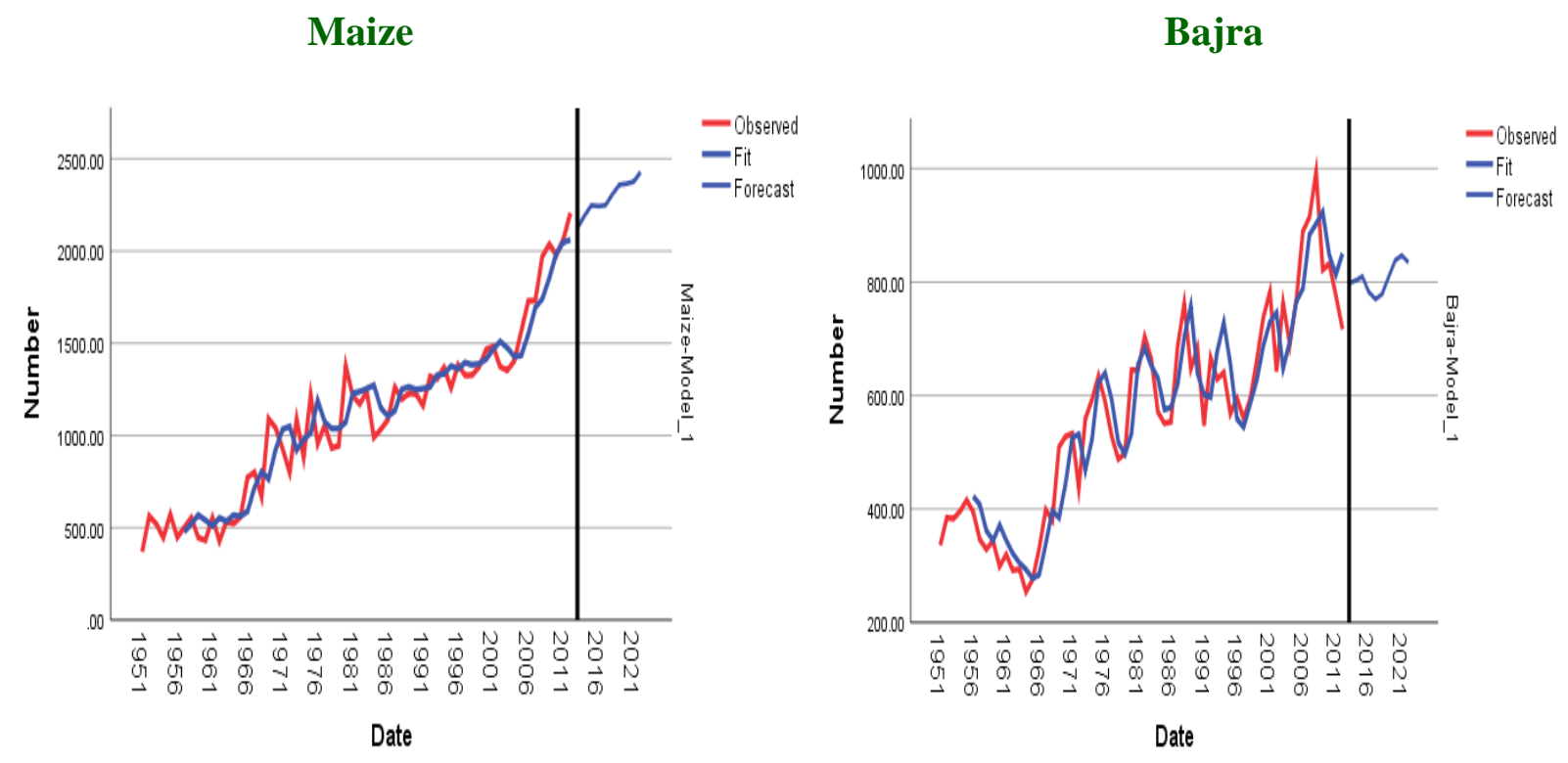

\section{Total Cereals}

Total pulses
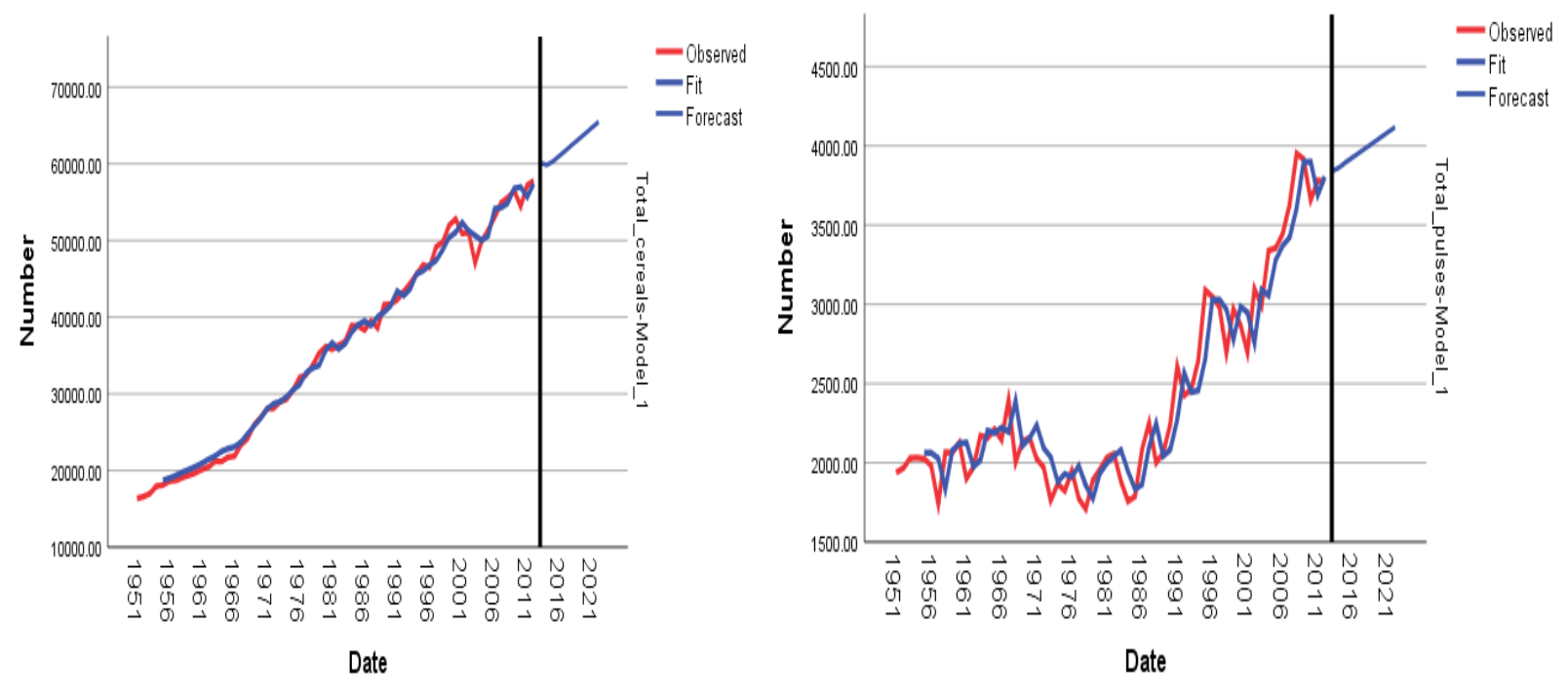
Total Oilseeds

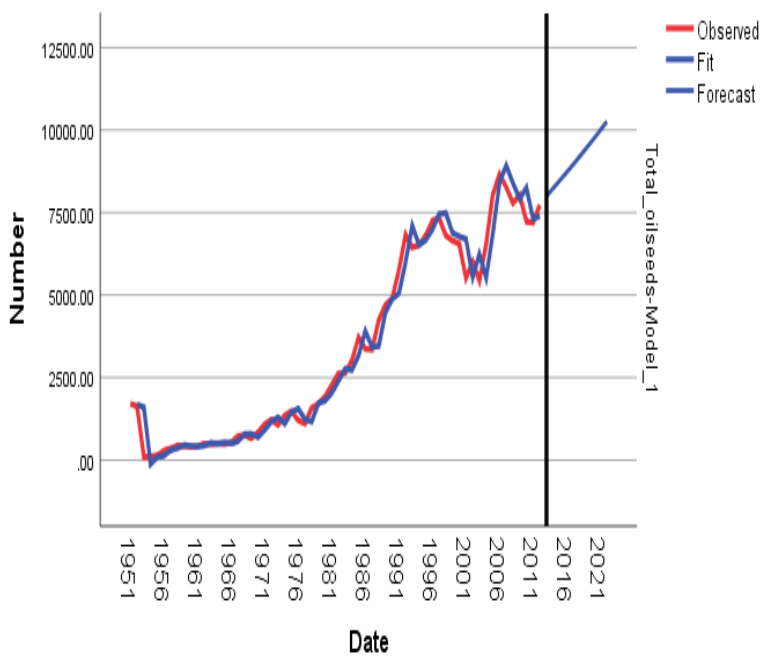

Sugarcane

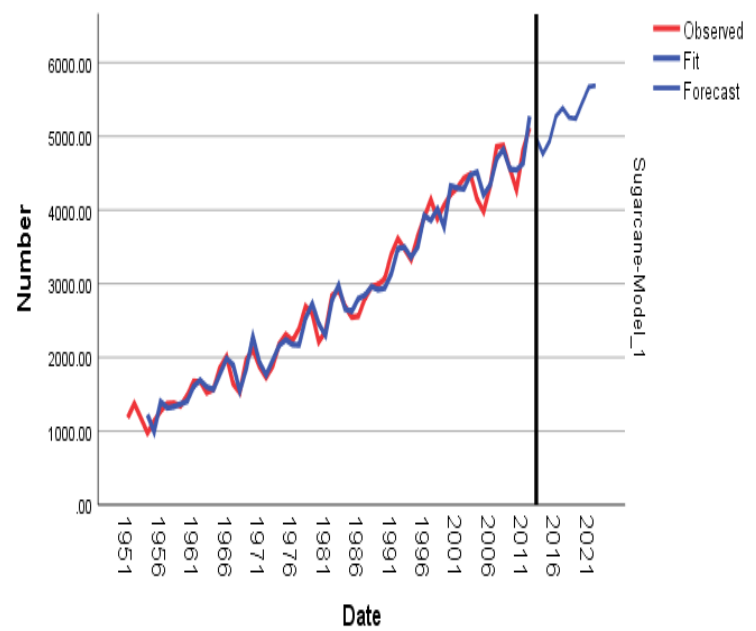

From figure 3, shows that all crops are forecasted as increasing order. The irrigated area under major crops shows a definite increasing from 1951 to 2022. It is revealed that by the time the use of irrigation increased for different crops as a result, the area for irrigation has also been increased.

In this present analysis, it is tried to fit the best model to forecast the irrigated area under major crops in India. Best fitted model is selected on the basis of maximum $\mathrm{R}^{2}$, error (RMSE), (MAPE), (MaxAPE), (MaxAE),

\section{Cotton}

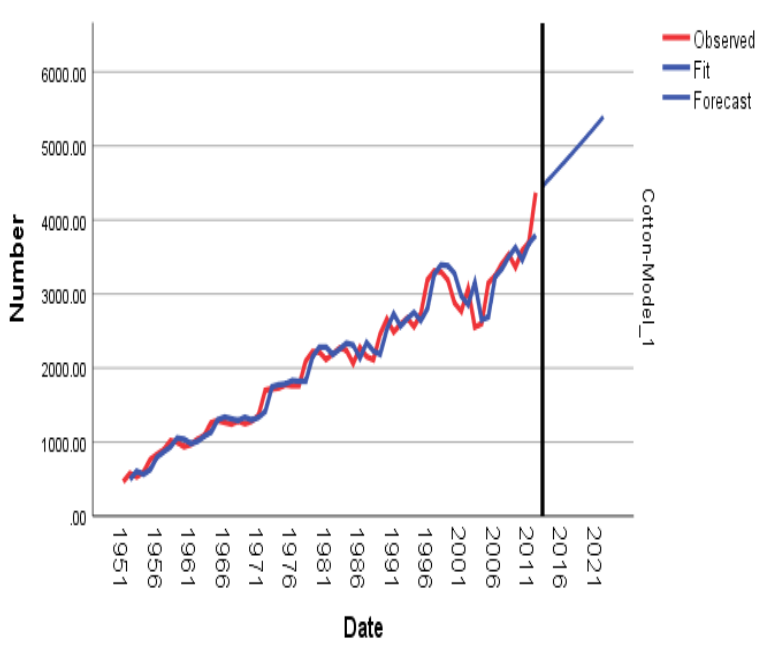

Tobacco

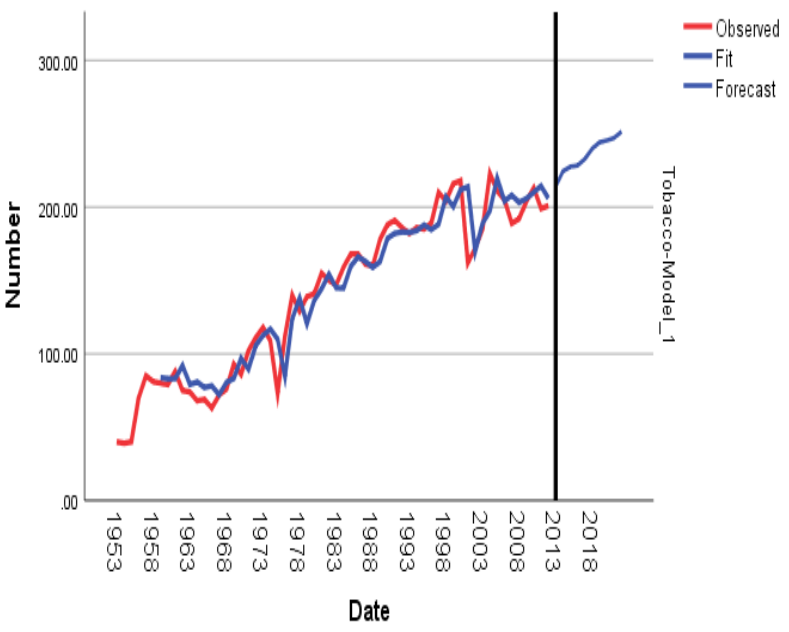

minimum of Normalized BIC following these different model criteria is used. Model validation has been done to forecast which showed that the irrigated area under major crops has been increased from 2013 to 2015 . To satisfy this condition, sometimes it was considered more than 5\% level of significance.

\section{References}

Abdullah F and Hossain Md.M. (2015). Forecasting of Wheat Production in 
Kushtia District \& Bangladesh by ARIMA Model: An Application of Box-Jenkin's Method. Journal of Statistics Applications \& Probability. 4 (3). $465-474$.

Bhadhuri A, Amarasinghe UA and Shah TN. (2012). An Analysis of Ground water Irrigation Expansion in India. An Analysis of Groundwater Irrigation Expansion in India. International Journal of Environment and Waste Management 9(3/4).

Biswas B, Dhaliwal LK, Singh SP and Sandhu SK. (2015). Forecasting wheat production using ARIMA model in Punjab. International Journal of Agricultural Sciences. 10: 158-161.

Box G and Jenkins G (1970). Time Series Analysis: Forecasting and Control. San.Brown LR. (2003). Outgrowing the Earth: The Food Security Challenge.

Choudhary N, Saurav S, Kumar RR and Budhlakoti N. (2017). Modelling and Forecasting of Total Area, Irrigated Area, Production and Productivity of Important Cereal Crops in India towards Food Security. International Journal of Current Microbiology Applied Sciences. 10: 2591-2600.

GOI. (1999). Integrated Water Resource Development - A Plan for Action. Report of the National Commission for Integrated. Water Resources Development, Vol. - I. Ministry of Water Resources of India, Government of India, New Delhi.

Hamjah MA. (2014). Rice Production Forecasting in Bangladesh: An Application of Box-Jenkins ARIMA Model. Mathematical Theory and Modeling. 4(4).

Hemavathi M and Prabakaran K. (2018). ARIMA Model for Forecasting of Area, Production and Productivity of Rice and Its Growth Status in Thanjavur District of Tamil Nadu, India. International Journal of Current Microbiology and Applied Sciences. 7(2):149-156.

Khan K, Khan G, Shaikh SA and Lodhi AS. (2015). ARIMA Modelling for Forecasting of Rice Production: A Case Study of Pakistan. Lasbela University Journal of Science and Technology. 4:117-120.

Kumar P. (1998).Food Demand and supply Projections for India. Agricultural Economics Policy Paper 98-01.IARI, New Delhi.

Patowary AN, Bhuyan PC, Dutta MP, Hazarika J and Hazarika PJ. (2017). Development of a Time Series Model to Forecast Wheat Production in India. Environment \& Ecology. 35(4D): 3313-3318.

Persaud S and Stacey R. (2003). India's Consumer and Producer Price Policies: Implications for Food Security. Economics Research Service, Food Security Assessment, GFA-14, Feb.

\section{How to cite this article:}

Sanjeeta Biswas and Banjul Bhattacharyya. 2019. A Time Series Modelling and Forecasting of Irrigated Area under Major Crops in India using ARIMA Models. Int.J.Curr.Microbiol.App.Sci. 8(12): 2383-2398. doi: https://doi.org/10.20546/ijcmas.2019.812.281 